\title{
A Note on the Translation
}

Where an English-language edition of a referenced volume is available, this is cited in the text under the translator's name. The full reference to a translated volume is cited in the Bibliography of English-language Versions.

The original edition of a referenced volume is cited in the Notes, so that both editions are made available to the reader. Where an Englishlanguage version of a text is not cited, the translation is my own.

Caroline Higgitt 
